\title{
VARIATIONS IN THE NUMBER AND MORPHOLOGY OF CUSPS OF AORTIC VALVE- ANATOMICAL AND SURGICAL RELEVANCE
}

\author{
Ashalatha P. R' ${ }^{1}$ Padmini Hannah Noone ${ }^{2}$
}

${ }^{1}$ Associate Professor, Department of Anatomy, Government Medical College, Kozhikode.

${ }^{2}$ Associate Professor, Department of Forensic Medicine, Vydehi Institute of Medical Science \& Research, Bangalore.

ABSTRACT

\section{BACKGROUND}

The human aortic valve is a vital structure and knowledge about its normal anatomy is important in detecting valve diseases and in valve replacement surgeries. The normal aortic valve has three semilunar leaflets or cusps, supported within the three aortic sinuses of Valsalva. The valve is known to exhibit anatomical variations with respect to number, shape and size of cusps, circumference and presence of fenestrations. The aim of the study is to detect and document the variations with respect to the number and morphology of the cusps of aortic valve. A prospective observational type of study on 210 random autopsy cases during a period of 6 months with age ranging from 21/2 years to 89 years was conducted in the Dept. of Forensic Medicine, Govt. Medical College, Kozhikode, after getting consent from Institutional Ethics Committee.

\section{MATERIALS AND METHODS}

Aortic valves from hearts dissected at autopsy were washed thoroughly and fixed in $10 \%$ formalin. Each specimen was numbered systematically. Morphological changes and anatomical variations of the aortic cusps were noted. Relation to cause of death, if any, was also noted.

\section{RESULTS}

1. Of the 210 cases studied, 208 aortic valves had three cusps (99.06\%), 1 case had a bicuspid aortic valve (0.47\%) and one had a quadricuspid valve (0.47\%). 2. Fenestrations were seen in 110 valves (52\%). 3. Cusps were asymmetrical in 54 aortic valves (25.71\%). 4. Lambl's excrescences were seen in 21 cases (10\%). 5. Only one case of bicuspid aortic valve with aortic stenosis was associated with sudden cardiac death. Other anomalies were not associated with cardiac cause of death.

\section{CONCLUSION}

The anatomical variations and morphological changes occurring in the aortic valve have significant clinical relevance in the diagnosis, prognosis, management and prevention of valve diseases, valve repair and valve replacement surgeries.

\section{KEYWORDS}

Aortic Valve, Aortic Valve Abnormalities.

HOW TO CITE THIS ARTICLE: Ashalatha PR, Noone PH. Variations in the number and morphology of cusps of aortic valveanatomical and surgical relevance. J. Evolution Med. Dent. Sci. 2017;6(9):694-698, DOI: 10.14260/Jemds/2017/150

\section{BACKGROUND \\ An increase in the frequent use of conservative surgical techniques for repairing or replacing damaged valves has generated an interest in the anatomy of valves. Thromboembolism, ruptures, restenosis and calcifications in the prosthetic valves are the major causes of morbidity and mortality in patients. This shows the necessity to develop a substitute of the natural valve, with minimum complications. \\ The aortic and pulmonary valves are the semilunar valves of the heart. The aortic valve is situated at the end of the aortic vestibule (the smooth left ventricular outflow tract) ${ }^{1}$ It has 3 semilunar leaflets or cusps supported within the three aortic sinuses of Valsalva. The free margin of each cusp contains a central fibrous nodule; from each side of this nodule, a thin smooth margin called the lunule extends up to the base of the cusp. ${ }^{2}$}

Financial or Other, Competing Interest: None.

Submission 23-12-2016, Peer Review 16-01-2017

Acceptance 23-01-2017, Published 30-01-2017.

Corresponding Author:

Dr. Ashalatha P. R,

Associate Professor, Department Of Anatomy,

Government Medical College,

Kozhikode-673008, Kerala.

E-mail: ashalathapr@rediffmail.com

DOI: $10.14260 /$ jemds $/ 2017 / 150$

\section{(c) (i) $\odot$}

Opposite the cusps, the vessel walls are slightly dilated to form the aortic sinuses. The coronary arteries arise from the anterior and left posterior aortic sinuses. The anterior aortic sinus is also called the right coronary sinus because of the origin of right coronary artery (RCA). The left posterior sinus is called the left coronary sinus because the left coronary artery (LCA) usually arises here. The right posterior sinus is often called the non-coronary sinus, because no coronary arteries arise from it.

Sinotubular junction (STJ) is the point in the ascending aorta, where the aortic sinuses end and the aorta becomes a tubular structure.

\section{Development ${ }^{3}$}

The pulmonary and aortic valves are derived from endocardial cushions that are formed at the junction of the truncus arteriosus and the conus. Two cushions, right and left, appear in the wall of the conus. They grow and fuse with each other with the separation of the aortic and pulmonary orifices. The right and left cushions are subdivided into two parts, one part going to each orifice. Simultaneously two more endocardial cushions develop -anterior and posterior. As a result, the aortic and pulmonary openings each have three cushions, from which 3 cusps of the valves develop.

The pulmonary valve is at first ventral to the aortic valve. Subsequently, there is a rotation, so that the pulmonary valve 
comes to the ventral and to the left of the aortic valve. After this rotation, the cusps acquire their definitive relationships as follows. Aortic valve- 1 anterior (Right) and two posterior (Left posterior, right posterior): Pulmonary valve-1 posterior, 2 anterior.

\section{MATERIALS AND METHODS}

The prospective observational study was conducted in the mortuary, Department of Forensic Medicine, Govt. Medical College, Kozhikode, Kerala. The hearts were obtained from 210 random autopsies. The age of the subjects ranged from $2 \frac{1}{2}$ years to 89 years. All cases except those showing decomposition, trauma involving the valve and unknown identity were included in the study.

The hearts, after autopsy, were washed thoroughly in tap water. Weight of the heart and the thickness of ventricles were noted. All the 4 valves-aortic, pulmonary, tricuspid and mitral-were examined. The aortic valves were removed by trimming the ascending aorta $1-2 \mathrm{~cm}$ above and below the valves, numbered systematically and immersed in $10 \%$ formalin for 24-72 hours.

The valves were stretched, pinned to a wooden board with drawing pins and circumference was measured using a ruler to the nearest millimeter. The horizontal (Intercommissural) length and vertical length of each cusp was also measured. Other anatomical features like asymmetry of the cusps, number of cusps, calcification, presence or absence of fenestrations, other cardiac anomalies were also noted.

Photographs were taken. Other parameters like age, sex, height, weight, associated congenital anomalies, if any, were also recorded.

\section{RESULTS}

\section{Number of Cusps}

Normal aortic valve with three cusps or leaflets was present in 208 cases out of 210 (99.06\%). Quadricuspid aortic valve was seen in one heart $(0.47 \%)$ (Fig. 1$)$ and bicuspid in one (0.47\%) (Fig. 2).

\section{Quadricuspid Aortic Valve}

This was found in a 45-year-old male. The cause of death was non-cardiac. The heart weighed 400 gms. Thickness of ventricles was normal. The circumference of the aortic valve was $7 \mathrm{~cm}$. The dimensions of the cusps are shown in Table. 1

From the table, it is evident that one cusp is large, two intermediate and one small. This type comes under the ' $\mathrm{D}$ ' type of Hurwitz and Roberts ${ }^{4}$ classification of quadricuspid aortic valves.

All the four cusps had small fenestrations. There were no cardiac anomalies.

\section{Bicuspid Aortic Valve}

A 32-year-old male collapsed while playing football and was brought dead to the casualty. Autopsy revealed features of left ventricular failure. The aortic valve had two calcified, distorted cusps, located anteroposteriorly. Circumference of the valve was $3.6 \mathrm{~cm}$. When the two cusps were approximated, there was a large gap. The deceased might have had severe aortic stenosis and regurgitation, leading to left ventricular hypertrophy. The situation was worsened by vigorous exercise.
No Other Cardiac Anomalies were detected

\section{Asymmetry of Cusps}

In the present study, 54 aortic valves (25\%) showed asymmetrical cusps (Fig. 3 ) as shown in Table 2

The intercommissural distance of each cusp was measured in the 21 valves which had 3 cusps of different sizes. The non-coronary cusp was largest in 12 , the right coronary in 6 and left coronary in 3 valves

\section{Fenestrations}

Out of 210 valves, 110 showed fenestrations (52\%) (fig. 4). The size and shape of the fenestrations varied, starting from pinhole size to $0.5 \mathrm{~cm}$. Lowest age in which the valve showed fenestrations was $2 \frac{1}{2}$ years- only one cusp had a small hole. But in an 89-year-old male, none of the cusps had fenestrations.

The details of fenestrations and cusps affected is summarized in Table 3 . When one cusp alone showed fenestrations, the left cusp was the most affected and noncoronary was the least affected.

\section{Lambl's Excrescences}

Small filiform processes-the Lambl's excrescences ${ }^{5}$ (Fig. 5) were found in 21 valves out of 210 (10\%), of which 20 were in adult males and one in an adult female. All three cusps showed Lambl's excrescences in 3 cases; two cusps in 8 cases and only one cusp showed these processes in 10 cases ( 5 non-coronary, 4 left coronary and 1 right coronary cusp).

Cause of death in all the 21 cases was non-cardiac and none of the deceased had cardioembolism.

In the present study, the lowest age in which excrescences were seen was 27 years and highest, 88 years.

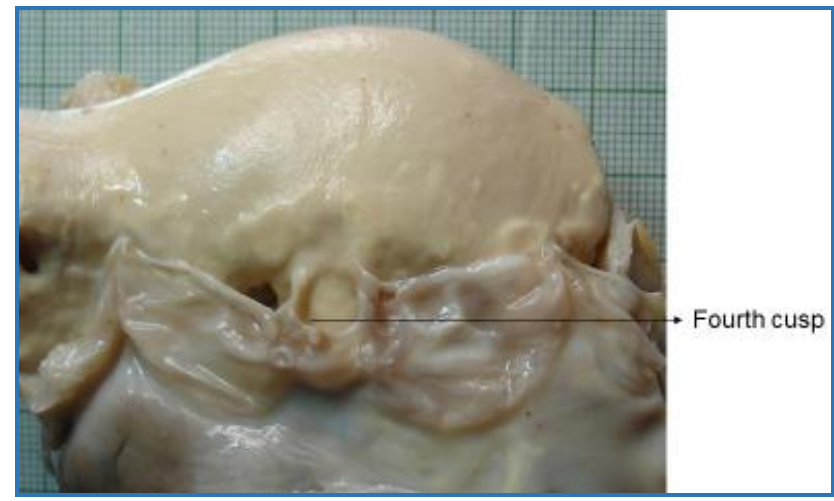

Figure 1. Quadricuspid Aortic Valve

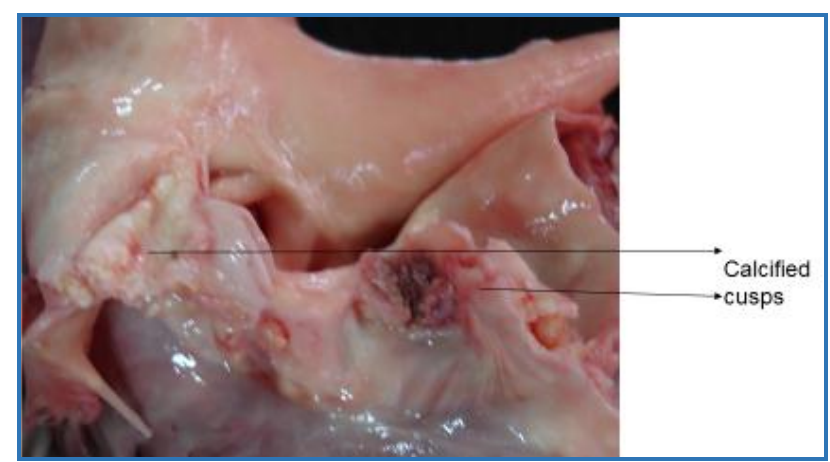

Figure 2. Bicuspid Aortic Valve 


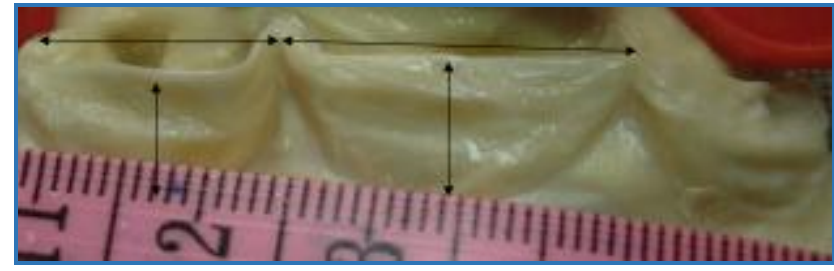

Figure 3. Asymmetry of Cusps

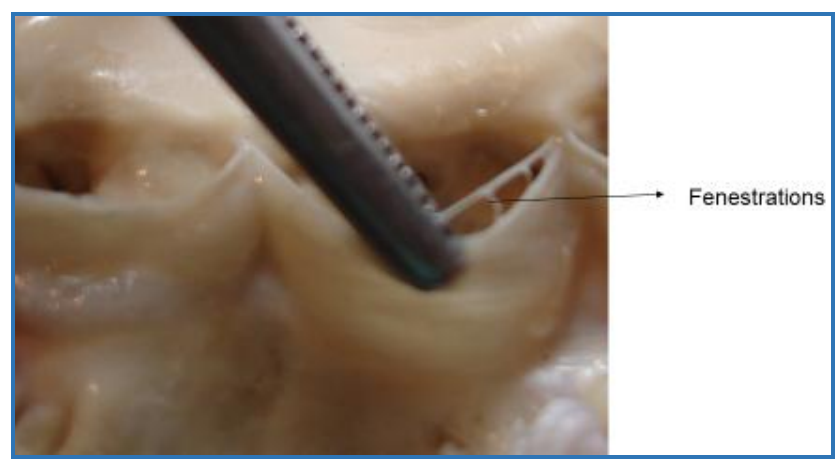

Figure 4. Fenestrations

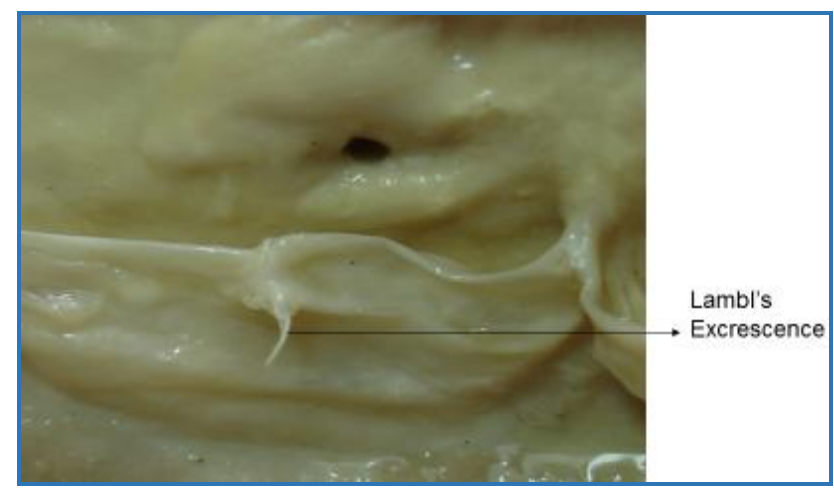

Figure 5. Lambl's Excrescence

\begin{tabular}{|c|c|c|c|c|}
\hline Measurement & $\begin{array}{c}\text { Left } \\
\text { Cusp } \\
\text { (cm) }\end{array}$ & $\begin{array}{c}\text { Right } \\
\text { Cusp } \\
\text { (cm) }\end{array}$ & $\begin{array}{c}\text { 4th } \\
\text { Cusp } \\
\text { (cm) }\end{array}$ & $\begin{array}{c}\text { Non- } \\
\text { Coronary } \\
\text { Cusp (cm) }\end{array}$ \\
\hline $\begin{array}{c}\text { Horizontal } \\
\text { (Intercommissural) }\end{array}$ & 2 & 2 & 1 & 2 \\
\hline Vertical & 1.1 & 1.1 & 0.6 & 1.5 \\
\hline Table 1. Measurements of Quadricuspid Aortic Valve \\
\hline
\end{tabular}

\begin{tabular}{|c|c|c|}
\hline No. of Valves & Size of Cusps & Percentage \\
\hline 155 & Three Equal Size & 73.81 \\
\hline 21 & Three Different Sizes & 10 \\
\hline 32 & 2 Equal Large, 1 Small & 15.23 \\
\hline 1 Quadricuspid & $\begin{array}{c}\text { 1 Large, 2 Intermediate, } \\
\text { 1 Small }\end{array}$ & 0.47 \\
\hline 1 Bicuspid & 2 Equal & 0.47 \\
\hline \multicolumn{2}{|c|}{ Table 2. Asymmetry of Cusps } \\
\hline
\end{tabular}

\begin{tabular}{|c|c|c|c|c|}
\hline $\begin{array}{c}\text { None of the } \\
\text { Cusps } \\
\text { Affected }\end{array}$ & $\begin{array}{c}\text { One Cusp } \\
\text { Only }\end{array}$ & 2 Cusps & $\begin{array}{c}\text { All Three } \\
\text { Cusps }\end{array}$ & $\begin{array}{c}\text { All Four } \\
\text { Cusps }\end{array}$ \\
\hline 100 & 39 & 46 & 24 & 1 \\
\hline $48 \%$ & $18.57 \%$ & $21.9 \%$ & $11.42 \%$ & $0.47 \%$ \\
\hline \multicolumn{2}{|c|}{ Table 3. Fenestrations and Cusps Affected } \\
\hline
\end{tabular}

\begin{tabular}{|c|c|c|c|c|c|}
\hline Authors & $\begin{array}{c}\text { 3 Equal } \\
\text { Sized } \\
\text { Cusps }\end{array}$ & $\begin{array}{c}\text { 2 Equal } \\
\text { and } \\
\text { 1 Small }\end{array}$ & $\begin{array}{c}\text { 3 Different } \\
\text { Sized } \\
\text { Cusps }\end{array}$ & $\begin{array}{c}\mathbf{4} \\
\text { Cusps }\end{array}$ & $\begin{array}{c}\mathbf{2} \\
\text { Cusps }\end{array}$ \\
\hline $\begin{array}{c}\text { Lee } \\
\text { Joseph } \\
\text { et al }\end{array}$ & $98.6 \%$ & 0 & $1.4 \%$ & - & - \\
\hline $\begin{array}{c}\text { Present } \\
\text { Study }\end{array}$ & $73.81 \%$ & $15.23 \%$ & $10 \%$ & $0.47 \%$ & $0.47 \%$ \\
\hline \multicolumn{6}{|c|}{ Table 4. Asymmetry of cusps - comparison of studies } \\
\hline
\end{tabular}

\begin{tabular}{|c|c|c|c|}
\hline Authors & Largest & Intermediate & Smallest \\
\hline Marcelo Biscelgi et al & $\mathrm{NC}$ & $\mathrm{LC}$ & $\mathrm{RC}$ \\
\hline Volleberg and Becker & $\mathrm{RC}$ & $\mathrm{NC}$ & $\mathrm{LC}$ \\
\hline Present Study & $\mathrm{NC}$ & $\mathrm{RC}$ & $\mathrm{LC}$ \\
\hline \multicolumn{2}{|r|}{ Table 5. Comparison of intercommissural } \\
distance of cusps \\
\hline
\end{tabular}

NC: Non Coronary; RC : Right Coronary; LC : Left Coronary

\section{DISCUSSION}

Variations in the Number of CUSPS

The Quadricuspid Aortic Valve (QAV)

The QAV is a rare congenital heart disease. In 1923, Simonds ${ }^{6}$ found 2 cases of QAV in 25,666 autopsies, an incidence of $0.008 \%$. After the advent of echocardiography, QAV have been diagnosed more frequently. Feldman et al at the Mayo Clinic $^{7}$ detected 8 cases of QAV among 60,446 patients, during echocardiography (Incidence of $0.013 \%$ ) for the period of 1982-88. For the period 1987-88, 6 cases were identified by the authors among 13,805 examinations (Incidence of $0.043 \%$ ).

In 1883, Dilg8 found 2 cases of QAV in a literature review. According to this review, a 34-year-old woman with QAV was reported by Balington in $1862,{ }^{9}$ probably the $1^{\text {st }}$ case of QAV reported. Oktay Tutarel of Hannover Medical School, Germany ${ }^{10}$ did a literature search and a total of 186 cases with a QAV was identified.

In 1973, Hurwitz and Roberts 4 classified the QAV according to their anatomic variation. They described 7 variations.

A - Four equal cusps.

B - Three equal and one smaller cusp.

C - 2 equal larger and 2 equal smaller.

D - One large, 2 intermediate and 1 small.

E - Three equal cusps and one larger cusp.

$\mathrm{F}$ - Two equal larger and two unequal smaller.

G - Four unequal cusps.

The QAV is said to be associated with other congenital cardiac malformations such as hypertrophic cardiomyopathy or ASD. Coronary arterial anomalies were the most common defect associated with QAV, which was of high significance during aortic valve surgery.

M. Serdar Kuchukoglu ${ }^{11}$ et al reported a case of QAV associated with AS and AR in a 26-year-old woman, diagnosed by Two-dimensional echocardiography. 4 cusps were of equal size and of normal texture-Type A.

Jonathen Timperley et al $^{12}$ diagnosed 3 cases of quadricuspid aortic valve during echocardiographic examination and one found unexpectedly during aortic valve replacement. 
Olson et al ${ }^{13}$ observed an incidence of $1 \%$ of QAV on review of 225 patients undergoing surgery for pure aortic insufficiency.

\section{Embryology 12}

The embryology of QAV is unknown. A variety of mechanisms have been postulated.

1. Anomalous septation of the truncus arteriosus.

2. Excavation of one of the endocardial cushions.

3. Septation of a normal valve cushion because of inflammation.

4. Division of one of the 3 endocardial cushions that normally give rise to three cusps.

Even though Type A and B were said to be the commonest in literature, in the present study, we found 'D' type of QAV. All the four cusps had small fenestrations. They were too small to produce aortic regurgitation. There were no cardiac anomalies. Origin and branching pattern of coronary arteries were normal.

There is one case report by Clothrap et al 14 on the presence of large fenestrations in all leaflets of a quadricuspid aortic valve leading to AR.

\section{Bicuspid Aortic Valve (BAV)}

BAV is the commonest congenital cardiac abnormality ${ }^{15}$ with an estimated prevalence of $1-2 \%$. Sir William Osler was one of the first to recognize the bicuspid aortic valve. It is almost three times more common in males than females. A BAV is composed of two leaflets, the commonest configuration of the bicuspid valve has the two commissures located in an anteroposterior direction with left and right cusps.

There can be several associated non valvular lesions. Most patients with BAV have a left dominant coronary circulation. This left coronary can arise from the pulmonary artery. ${ }^{15}$ BAV can be associated with other left sided obstructive lesions such as aortic stenosis, coarctation of aorta and ventricular septal defect, suggesting a common developmental mechanism. Specific gene mutation have been isolated.

Linda Cripe, GregorAndelfinger ${ }^{16}$ et al statistically tested whether BAV is associated with genetic inheritance and found out that the heritability of BAV and BAV and/or CVMs were $89 \%$ and $75 \%$ respectively.

It is now accepted that BAV is heritable. ${ }^{15}$ There is a $10 \%$ chance of $1^{\text {st }}$ degree relative having a bicuspid aortic valve in patients with BAV disease. Mutations in a gene called NOTCH1, were noted in two families with BAV. So, the American College of Cardiology/American Heart Association recommends that all patients with a $1^{\text {st }}$ degree relative with BAV should be evaluated for BAV and aortopathy. ${ }^{15}$

\section{Clinical Progression of BAV}

Range from severe aortic stenosis in childhood to asymptomatic disease until old age. In 75\%, progressive fibrocalcific stenosis can occur which can lead to sudden death. Paul WM Fedak, Subodh Verma et al have described the Clinical and Pathophysiological Implications of a BAV. ${ }^{17}$ Patients with poor lipid profiles and those who smoke are at a high risk of developing aortic stenosis. So, by avoiding these risk factors, chances of developing AS can be minimised.
In the present study, the aortic valve had two calcified, distorted cusps, located anteroposteriorly. There was evidence of aortic stenosis, regurgitation, left ventricular hypertrophy and failure, which led to sudden death.

\section{Asymmetry of Cusps}

Lee Joseph et al18 in a case control study, reported that the presence of asymmetry among AV cusps is strongly associated with the future development of AS. In the present study, 54 aortic valves (25\%) showed asymmetrical cusps. A comparison of the present study with that of Lee Joseph et al is shown in Table 4.

In the present study, the number of valves with three equal sized cusps are less than that of Lee Joseph et al and number of valves with three different sized cusps is higher.

A comparison of inter commissural distance of the three cusps is shown in Table 5 According to a study conducted by Marcelo Biscelgi et al ${ }^{19}$ the non-coronary cusp is the largest. In the present study also, non-coronary cusps were the largest when the cusps showed asymmetry. Left coronary cusps were found to be the smallest in the present study as well as in the study conducted by Vollebergh and Becke.20

\section{Fenestrations in Cusps}

Fenestrations of the aortic valve rarely produce significant valvular regurgitation. ${ }^{1}$ But, when unusually large or multiple, they can lead to massive aortic regurgitation (AR), mostly in patients with chronic hypertension and/or aortic annular dilation. Rheumatic aortic regurgitation has been reported in a patient with large congenital fenestrations in all three leaflets by AhmadrezaJodati et al. ${ }^{21}$

Hope $^{22}$ (1842) and Rokitansky ${ }^{23}$ (1852) were the first to describe aortic cusp fenestrations. Foxe ${ }^{24}$ conducted the first systematic study of fenestration of the semilunar valves of the human heart in 300 autopsies and found one or more fenestrations in $82 \%$ of all cases. He also concluded that the frequency of fenestrations increases with age.

Acute rupture of the fenestrated cusp, either spontaneously or because of infection can also lead to massive AR resulting in acute left heart failure. ${ }^{21}$

In the present study, out of 210 valves, 110 showed fenestrations (52\%). Foxe has reported a higher incidence of fenestrations $(82 \%)$ The size and shape of the fenestrations varied, starting from pinhole size to $0.5 \mathrm{~cm}$. Lowest age in which the valve showed fenestrations was $2 \frac{1}{2} 2$ year- only one cusp had a small hole. But in an 89-year-old male, none of the cusps had fenestrations. A relation between age and sex with occurrence of fenestrations was not seen in the present study. All the four cusps of the quadricuspid aortic valve showed small fenestrations. A similar finding was also reported in literature, with large fenestrations resulting in regurgitation by Clothrap WH and Warren ET.14

\section{Lambl's Excrescences}

In 1856, Lambl ${ }^{5}$ first described small filiform processes on the ventricular surfaces of normal and abnormal aortic valves. In subsequent study of normal valves, a $70 \%$ to $90 \%$ prevalence of excrescences was reported, predominantly on the mitral (70-85\%) and aortic valves (62-90\%), but also on the right sided valves. They are seen in subjects $1-60$ years old, regardless of gender. Valve excrescences consist of a core of connective tissue covered by endothelium. 
Aetiology is uncertain. The constant movement of the cusps may lead to tearing of subendothelial collagen and elastic fibres, which subsequently endothelialize. This may explain their predominance on the left sided valves owing to large pressure differences. But the presence of excrescences on normal valves in children and adults of different age groups suggest that they may not result from an injury or age related process.

Valve excrescences have been reported with a frequency of up to $22 \%$ in patients with suspected cardioembolism referred for TEE. This finding has led to the suspicion that they are a substrate for embolism. Carlos A Roldan ${ }^{25}$ et al conducted a study on this topic and their findings are as follows: excrescences are common on the left heart valves, have a similar prevalence in normal subjects and in patients with or without suspected cardio embolism regardless of age and gender and do not appear to be associated with embolic events.

In the present study, excrescences were seen on mitral, tricuspid and aortic valves; they were not seen in pulmonary valves. Excrescences were seen only in adults (27-88 years) and there was a male predominance ( 20 males and one female).

\section{CONCLUSION}

Knowledge about the dimensions and morphology of aortic valve is essential for diagnosis, prognosis and planning surgical procedures. It will also be helpful in manufacturing prosthetic valves.

Because great majority of patients with QAV and asymmetric cusps can develop complications, careful clinical evaluation and follow up is necessary. As there is a heritable component in BAV, all first-degree relatives of a patient with BAV should be screened by echocardiography. Patients with BAV should have healthy lipid profiles and must stop smoking to prevent early onset of stenosis.

Patients with large fenestrations on the cusps can develop rupture of cusps or AR leading to acute LVF. Surgical repair can be done to prevent such complications.

\section{REFERENCES}

[1] Standring S. Gray's Anatomy. The anatomical basis of clinical practice. 41st edn. Chapter 57. Heart 2016: p. 1011.

[2] Chaurasia BD. Human Anatomy. Vol. 1. $7^{\text {th }}$ edn. New Delhi: CBS Publishers 2016: p. 275.

[3] Singh I. Human Embryology. Cardiovascular system. $10^{\text {th }}$ edn. New Delhi: Jaypee Brothers Medical Publishers (P) Ltd., 2014: P. 245.

[4] Hurwitz LE, Roberts WC. Quadricuspid Semilunar Valves. Am J Cardiol 1973;31(5):623-6.

[5] Lambl VA. Papillareexcrescenzen und der semilunarklappe der aorta. Wien Med Wochenschr 16 1856;244-50.

[6] Simonds JP. Congenital malformations of the aortic and pulmonary valves. Am J Med Sci 1923;166:584-95.

[7] Feldman BJ, Khandheria BK, Warnes CA, et al. Incidence, description and functional assessment of isolated quadricuspid aortic valves. Am J Cardiol 1990;65(13):937-8.

[8] Ding J. Ein beitragzur kenntnisseltener herzanomalienim anschluss an einen fall von angeborener linksseitiger conusstenose. Virchows Arch Pathol Anat 1883;91:193-259.

[9] Robicsek F, Sanger PW, Daugherty HK, et al. Congenital quadricuspid aortic valve with displacement of the left coronary orifice. Collected works on Cardiopulmonary Disease 1968;14:87-90.

[10] Tutarel 0 . The quadricuspid aortic valve: a comprehensive review. The Journal of Heart Valve Disease 2004;13(4):534-7.

[11] Kuchukoglu MS, Erdogan L, Okcun B, et al. Quadricuspid aortic valve abnormality associated with aortic stenosis and aortic insufficiency. Journal of the American Society of Echocardiography 2002;15(1):902.

[12] Timperley J, Milner R, Marshal AJ, et al. Quadricuspid aortic valve. South West Cardiothoracic Centre, Derriford hospital, Plymouth UK. Clin Cardiol 2002;25:548-52.

[13] Olson LJ, Subramanian R, Edwards WD. Surgical pathology of pure aortic insufficiency: a study of 225 cases. Mayo Clin Proc 1984;59(12):835-41.

[14] Colthrap WH, Warren ET, Health BJ. Quadricuspid aortic valve with centrally fenestrated leaflets causing aortic insufficiency. Texas Heart Inst J 1988;15(3): 187-8.

[15] Mordi I, Tzemos N. Bicuspid aortic valve disease: a comprehensive review. Cardiology Research and Practice Article ID 196037 2012;1012.

[16] Cripe L, Andelfinger G, Martin LJ, et al. Bicuspid aortic valve is heritable. J Am Col Cardiol 2004;44(1):138-43.

[17] Fedak PW, Verma S, David TE, et al. Dept. of Laboratory Medicine and Pathobiology, University of Toronto, Dept. of Pathology, Toronto General Hospital, Toronto, Canada. Clinical and pathophysiological implications of a bicuspid aortic valve. Circulation 2002;106(8):900-4.

[18] Joseph L, Krishnaswamy A, Tuzcu EM, et al. Relations of cuspal asymmetry to development of aortic stenosis in adults with tricuspid aortic valves. J Heart valve Dis 2014;23(4);395-405.

[19] Jatene MB, Monteiro R, Guimarães MH, et al. Aortic valve assessment. Anatomical study of 100 healthy human hearts. Arq Bras Cardiol 1999;73(1):75-86.

[20] Vollebergh FE, Becker AE. Minor congenital variations of cusp size in tricuspid aortic valves. possible link with isolated aortic stenosis. $\mathrm{Br}$ Heart J 1977;39(9):1006-11.

[21] Jodati A, Kazemi B, Safaei N. Rheumatic aortic regurgitation in a patient with large congenital fenestrations in all three leaflets. J Cardiovasc Thorac Res 2014;6(1):61-3.

[22] Hope I. A treatise on the diseases of the heart and great vessels. Philadelphia: Lea and Blanchard: 1842.

[23] Rokitansky C. Hand buch der pathologische Anatomie. Translated by Day GE. London: Sydenham Society 1852;4:228.

[24] Foxe AN. Fenestrations of the semilunar valves. Am J Path 1929;5(2):179-82.

[25] Roldan CA, Shively BK, Crawford MH, et al. Valve excrescences, prevalence, evolution and risk for cardio embolism. J Am Col Cardiol 1997;30(5):1308-14. 